\title{
Perancangan Aplikasi Alat Musik Tradisional Rebana Berbasis Android untuk Pembelajaran Ekstrakurikuler Hadrah di SLB B-C Nusantara Bangil Kab. Pasuruan
}

\author{
Teguh Arifianto ${ }^{1}$, Qonita Syarif Nurullah ${ }^{2}$, M. Aries Syufagi ${ }^{3}$ \\ Program Studi Teknik Informatika, STMIK Yadika Bangil \\ Email : teguh.arifianto.1988@stmik-yadika.ac.id', syarif.conit@gmail.com², \\ moh.aries.syufagi@gmail.com³
}

\begin{abstract}
ABSTRAK
Seiring pesatnya perkembangan komputer, aplikasi komputer juga berkembang dengan pesat dan menjadi salah satu hiburan utama untuk mengisi waktu luang baik dilakukan bersama atau pribadi. Pada era modern seperti sekarang, alat musik rebana telah mengalami kekurangan minat, kebanyakan alat musik rebana dimainkan oleh orang tua maupun ibu-ibu rumah tangga yang tergabung dalam sebuah grup tertentu. Padahal untuk memainkan alat musik rebana membutuhkan tenaga yang cukup besar pula. Anak-anak muda cenderung lebih suka memainkan alat musik modern seperti drum. Salah satu cara agar masyarakat mau mengenal serta mempelajari alat musik tradisional adalah dengan membuat suatu aplikasi pengenalan alat musik tradisional nusantara berbasis android yang alat musiknya dibuat dalam bentuk 3 dimensi menggunakan Blender agar menarik minat masyarakat untuk mempelajarinya Pemodelan sistem pada pembangunan aplikasi ini menggunakan Unity dan UML (Unified Modelling Language) dengan tools activity diagram, use case dan dikembangkan menggunakan model waterfall yang dijalankan pada sistem operasi android.
\end{abstract}

Kata kunci : rebana, alat musik tradisional, android, 3 dimensi, Blender

\section{PENDAHULUAN}

Di Indonesia, alat musik tradisional rebana berkembang menjadi banyak jenis. Biasanya merupakan ciri khas dari kultur budaya daerah tertentu. Jenis alat rebana yang paling umum diantaranya, rebana Banjar, rebana Biang, Jidor, Kompang, Marawis, Samroh, Hadroh dan lainnya.

Rebana atau dalam bahasa Inggris disebut tambourine adalah alat musik tepuk, pukul, perkusis, dan Islamis. Rebana dibuat dengan menggunakan papan kayu khusus dan pilihan. Kemudian dibulatkan dan dilubangi menggunakan mesin bubut bertenaga listrik. Perkembangan alat musik rebana di Indonesia dimulai ketika masuknya pengaruh Islam ke Indonesia. Alat musik mereka berupa gambus \& rebana. Dari proses itulah muncul orkes-orkes gambus di Indonesia hingga saat ini [1].

Permainan digital dapat dikatakan memberikan media yang sangat sesuai untuk menerapkan pelatihan dalam 
pemrosesan prediktif. Di sebuah bentuk yang relevan untuk mencapai tujuan permainan. Ini menciptakan sebuah lingkungan belajar yang sangat jauh berbeda dengan yang dialami dalam setting kelas tradisional dan mungkin saja terutama penting bagi peserta didik [2].

Android adalah sebuah sistem operasi untuk perangkat mobile berbasis Linux yang mencakup sistem operasi, middleware, dan aplikasi. Android menyediakan platform terbuka bagi para pengembang untuk menciptakan aplikasi mereka karena perangkat ini membuat hidup kita begitu manis, maka setiap versi android dinamai dari makanan penutup (dessert) [3].

Tujuan dari pembuatan aplikasi alat musik rebana dengan menggunakan unity yaitu untuk mengetahui cara membuat aplikasi alat musik rebana berbasis android dengan menggunakan unity, untuk alat pendukung ekstrakurikuler hadrah di SLB B-C Nusantara Bangil Kab. Pasuruan, untuk lebih memudahkan para siswa mengenalkan pengetahuan rebana, untuk mengetahui cara mengaplikasikan alat musik rebana berbasis android dengan menggunakan unity.

Manfaat dari pembuatan aplikasi alat musik rebana dengan menggunakan unity yaitu agar dapat mengetahui cara membuat aplikasi alat musik rebana berbasis android dengan menggunakan unity, agar memudahkan penenalan rebana pada anak SLB B-C Nusantara

Bangil Kab. Pasuruan, agar dapat mengetahui cara mengaplikasikan alat musik rebana berbasis android dengan menggunakan unity.

\section{METODE PENELITIAN}

Pada bagian metode penelitian ini diuraikan tentang metode yang diterapkan dalam penelitian ini. Oleh karena itu pada metode penelitian memuat:

1. Rancangan penelitian

Untuk memperjelas tahapan-tahapan yang akan dilakukan dalam penelititan ini, maka diperlukan suatu kerangka kerja penelitian yang menjelaskan tentang langkahlangkah yang perlu dilaksanakan guna menyelesaikan masalah yang dibahas dalam penelitian. Adapun kerangka kerja penelitian yang digunakan seperti berikut:

a. Rumusan Masalah

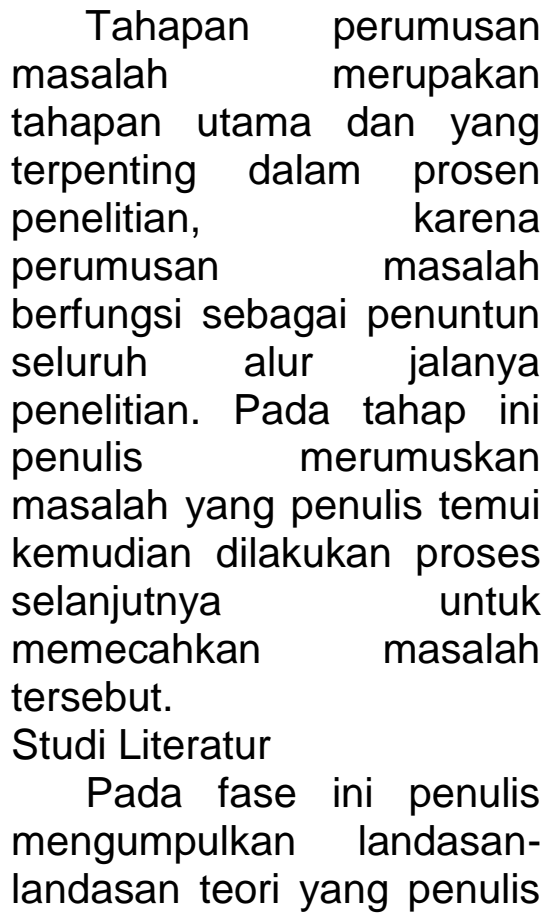


peroleh dari buku, jurnal ilmiah untuk melengkapi konsep-konsep dan teoriteori sehingga memiliki landasan yang tepat.

c. Pengumpulan Data

Di tahap ini penulis mengumpulkan data-data yang penulis butuhkan untuk melakukan penelitian, yang mana penulis menggunakan teknik pengumpulan data kuisioner dan observasi.

d. Analisis Data

Pada tahap ini, penulis melakukan analisis sistem yang berjalan dengan mengetahui kelemahan yang terjadi dan membuat solusi dengan merancang aplikasi pengenalan alat musik tradisional.

e. Pengembangan Sistem

Pada tahap ini dilakukan pengembangan sistem menggunakan berbagai bentuk pengembangan sistem dengan model-model pengembangan sistem yang ada.

f. Penulisan Laporan

Pada tahapan ini penulis membuat laporan yang disusun berdasarkan hasil seluruh penelitian yang telah dilakukan.

2. Analisis, Perancangan, dan Implementasi

Adapun metode sistem yang digunakan dalam penelitian ini yaitu menggunakan metode waterfall. Adapun model waterfall yang digunakan dapat dilihat pada gambar 1 .

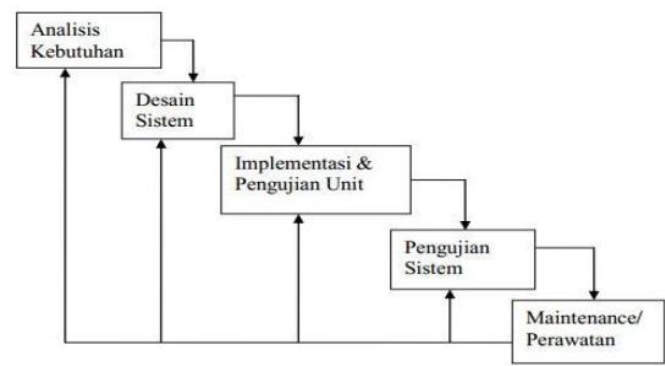

Gambar 1. Pengembangan software model waterfall

Adapun penjelasan dari metode pengembangan sistem yang terdapat pada gambar sebagai berikut:

a. Analisis

Kebutuhan pada tahap

ini penulis melakukan

pengumpulan data serta informasi yang di dapat dari hasil observasi dan kuisioner yang telah dibuat untuk mengetahui karakteristik alat musik rebana yang kemudian di analisis guna mendefinisikan kebutuhan yang harus dipenuhi oleh program yang akan dibangun.

b. Desain Sistem

Pada tahap ini setelah data dan informasi yang di butuhkan selesai di kumpulkan maka di lakukanlah proses desain mulai dari mendesain interface (tampilan), desain menu-menu pada program aplikasi yang akan di buat, mendesain alat musik rebana yang akan dibuat dalam bentuk 3D menggunakan aplikasi blender dan unity game engine, mendisain model sistem dengan use case 
diagram dan mendesain prosedur dari sistem menggunakan class diagram dan activity diagram.

\section{HASIL DAN PEMBAHASAN}

Use

case

diagram

menggambarkan fungsionalitas yang diharapkan dari sebuah sistem. Yang ditekankan adalah "apa" yang diperbuat sistem dan bukan "bagaimana". Sebuah use case mempresentasikan sebuah interaksi antara actor dengan sistem. Berikut adalah perancangan use case pada sistem pada gambar 2 .

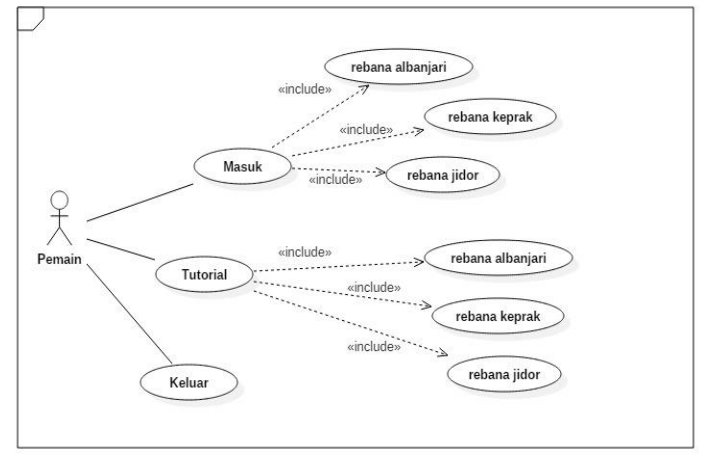

Gambar 2. Use case diagram

Interface atau rancangan antar muka dalam penelitian ini adalah sebagai berikut:

1. Halaman menu awal

Tampilan awal merupakan tampilan yang pertama kali dilihat user saat pertama kali menggunakan aplikasi ini, dimana pada tampilan awal pengguna dapat memilih beberapa menu yaitu Masuk, Tutorial, dan Keluar seperti pada gambar 3 .

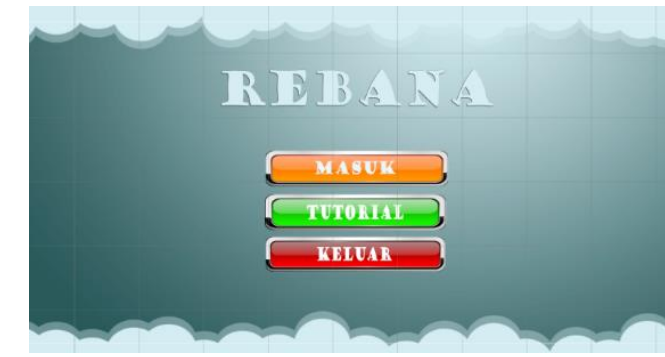

Gambar 3. Halaman menu awal

2. Halaman menu Masuk Halaman menu masuk terdapat 3 (tiga) pilihan yaitu rebana albanjari, keprak, dan jidor seperti pada gambar 4 .

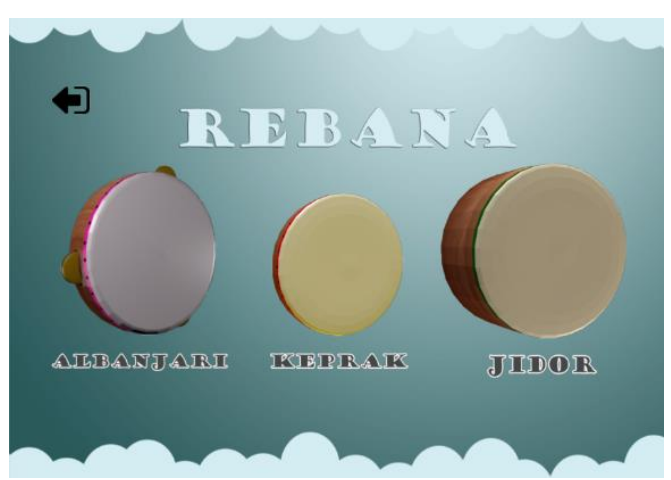

Gambar 4. Halaman menu Masuk

3. Halaman menu Rebana Albanjari

Halaman menu ini merupakan halaman yang menampilkan alat musik rebana Albanjari seperti pada gambar 5.

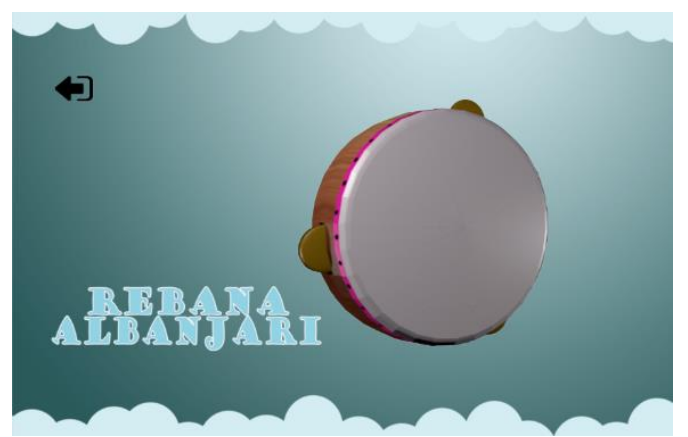

Gambar 5. Halaman menu Rebana Albanjari 
4. Halaman menu Rebana Keprak Halaman menu ini merupakan halaman yang menampilkan alat musik rebana Keprak seperti pada gambar 6 .

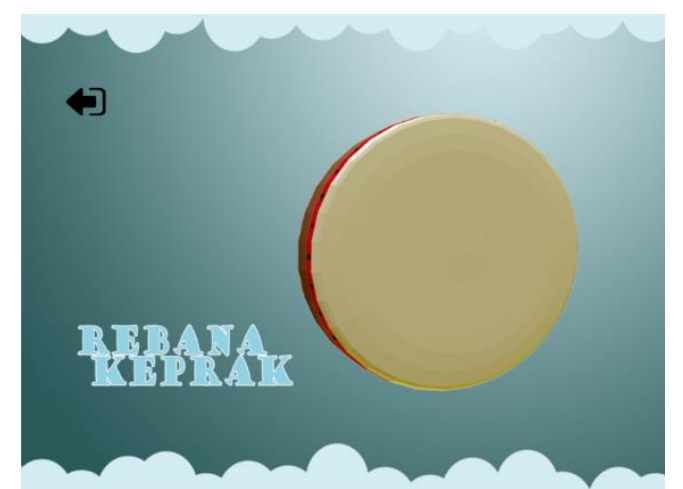

Gambar 6. Halaman menu Rebana Keprak

5. Halaman menu Rebana Jidor

Halaman menu ini merupakan halaman yang menampilkan alat musik rebana Jidor seperti pada gambar 7 .

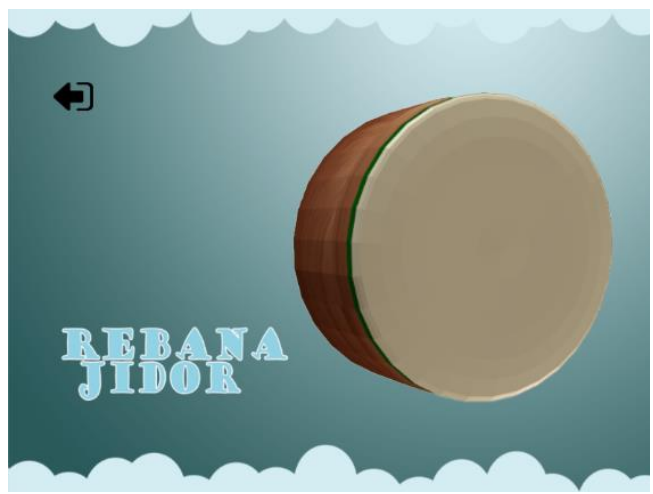

Gambar 7. Halaman menu Rebana Jidor

6. Halaman menu tutorial Rebana

Halaman menu ini merupakan halaman yang berisi menu pilihan tutorial rebana seperti seperti pada gambar 8 .

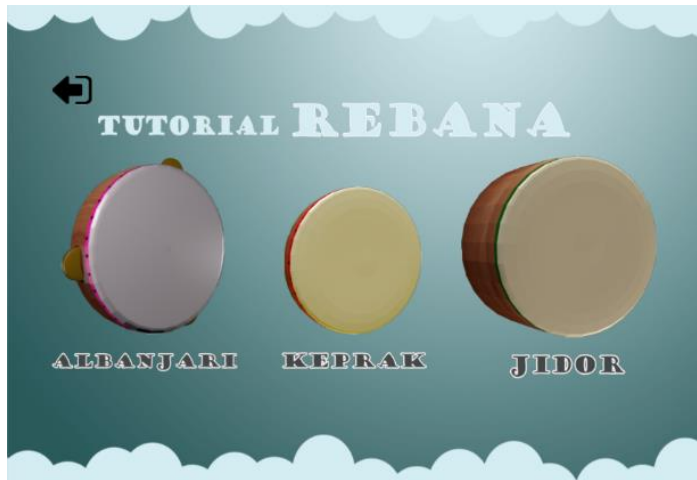

Gambar 8. Tampilan menu tutorial

7. Halaman tutorial Rebana Albanjari

Halaman ini akan ditunjukkan gambar asli dari rebana Albanjari dan terdapat tombol "PELAJARI" untuk mencoba tutorial rebana Albanjari seperti pada gambar 9 dan 10.

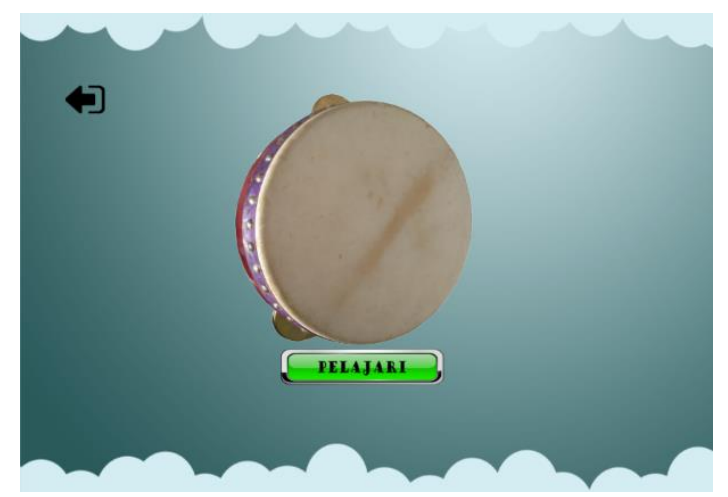

Gambar 9. Halaman tutorial Rebana Albanjari

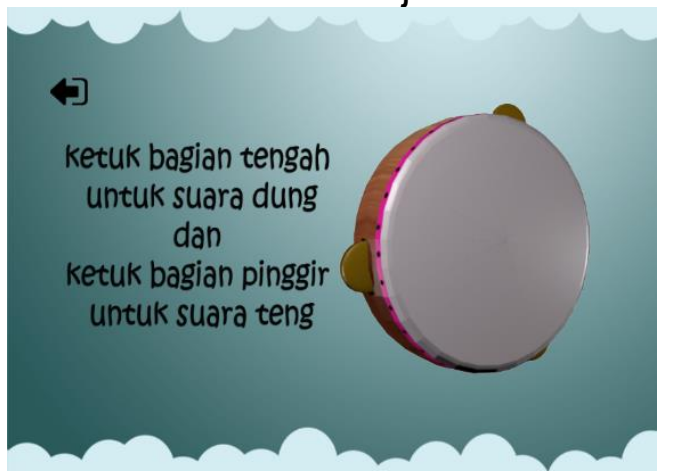

Gambar 10. Halaman tutorial Rebana Albanjari 
8. Halaman tutorial Rebana Keprak

Halaman ini akan ditunjukkan gambar asli dari rebana Keprak dan terdapat tombol "PELAJARI" untuk mencoba tutorial rebana Keprak seperti pada gambar 11 dan 12.

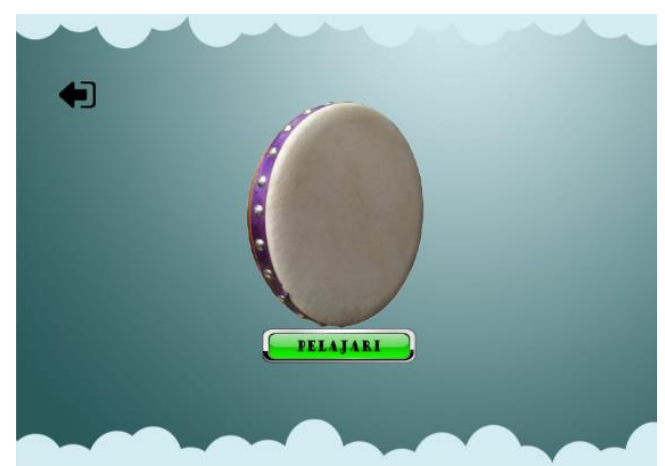

Gambar 11. Halaman tutorial Rebana Keprak

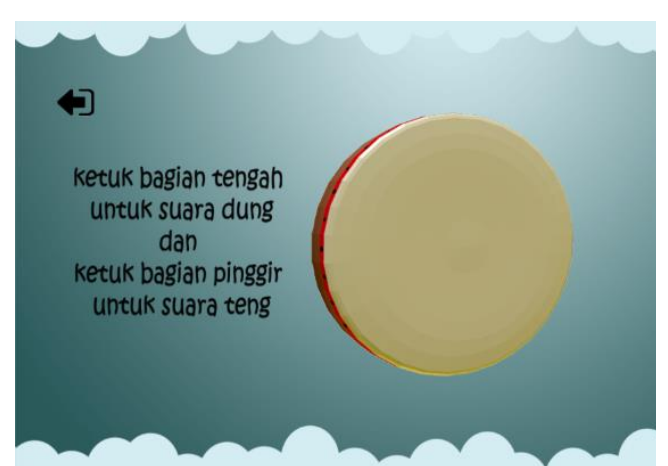

Gambar 12. Halaman tutorial Rebana Keprak

9. Halaman tutorial Rebana Jidor

Halaman ini akan ditunjukkan gambar asli dari rebana Jidor dan terdapat tombol "PELAJARI" untuk mencoba tutorial rebana Jidor seperti pada gambar 13 dan 14 .

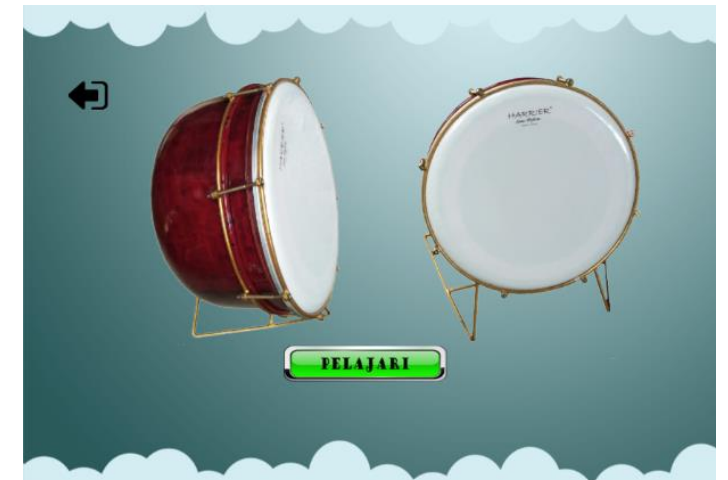

Gambar 13. Halaman tutorial Rebana Jidor

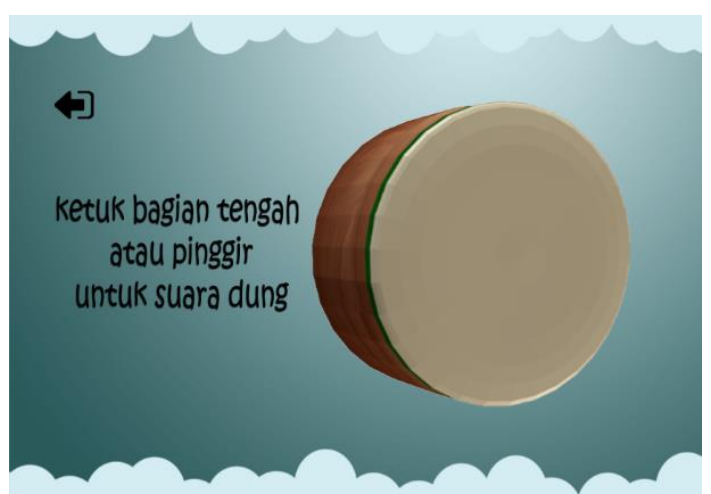

Gambar 14. Halaman tutorial Rebana Jidor

Uji coba aplikasi ini menggunakan metode black box testing yang diuji oleh user. Kriteria penilaian terdiri dari Bentuk, Animasi, Suara, Tampilan, dan Kemudahan memainkan seperti pada tabel 1 .

Tabel 1. Nilai ujicoba oleh user 1

\begin{tabular}{lrrrr}
\multicolumn{5}{c}{ sampai 4 } \\
\hline Penilaian & Use & Use & Use & Use \\
& r 1 & r 2 & r 3 & r 4 \\
\hline Bentuk & 4 & 3 & 4 & 4 \\
Animasi & 4 & 4 & 4 & 4 \\
Suara & 3 & 3 & 4 & 3 \\
Tampilan & 4 & 4 & 4 & 4 \\
Kemudaha & 4 & 4 & 4 & 4 \\
n & & & & \\
memainkan & \multicolumn{5}{c}{3,6} & 4 & 3,8 \\
Nilai rata- & 3,8 & 3,8 & \\
rata & \multicolumn{5}{c}{} \\
\hline
\end{tabular}


User mengisi dari angka 1 sampai dengan 4 dengan penilaian sebagai berikut:

a. Nilai dari Bentuk, Animasi, dan Suara

1. Tidak mirip

2. Sedikit mirip

3. Mirip

4. Sangat mirip

b. Nilai dari Tampilan

1. Tidak menarik

2. Sedikit menarik

3. Menarik

4. Sangat menarik

c. Nilai dari Kemudahan

1. Sangat sulit

2. Sedikit sulit

3. Sulit

4. Sangat mudah

Dari percobaan oleh user 1 sampai 4 dapat diketahui bahwa nilai rata-rata kesesuaian aplikasi rebana adalah 3,8 yaitu mendekati angka sempurna yaitu 4. Aplikasi ini dapat dikatakan sudah berjalan dengan baik.

\section{SIMPULAN}

Berdasarkan penelitian ini, dapat diambil sebuah simpulan bahwa disain aplikasi alat musik rebana berbasis android untuk pembelajaran ekstrakurikuler hadrah di SLB B-C Nusantara Bangil Kab. Pasuruan telah berjalan baik dengan nilai mendekati angka sempurna yaitu 3,8. Hal ini dibuktikan dengan pengujian sistem yang menggunakan pengujian dengan metode black box sistem terhadap aplikasi alat musik rebana berbasis android untuk pembelajaran ekstrakurikuler hadrah di SLB B-C Nusantara Bangil Kab. Pasuruan.

\section{PENELITIAN SELANJUTNYA}

Pada penelitian selanjutnya, dapat dikembangkan dengan menambahkan beberapa alat musik untuk menambah variasi alat musik tradisional rebana kemudian dikembangkan dengan menambahkan animasi pada saat alat musik dimainkan.

\section{DAFTAR PUSTAKA}

[1] I. H. Roemaldo Suares, Budi Suyanto, "Game Pembelajaran Alat Musik Tradisional," J. Tek. Elektro Terap., vol. 5, no. 1, pp. 5159, 2016.

[2] A. Schremm, A. Hed, M. Horne, and M. Roll, "Training predictive L2 processing with a digital game: Prototype promotes acquisition of anticipatory use of tone-suffix associations," Comput. Educ., vol. 114, pp. 206221, 2017.

[3] D. W. Putra, A. P. Nugroho, and E. W. Puspitarini, "Game Edukasi Berbasis Android Sebagai Media Pembelajaran Untuk Anak Usia Dini," J. Inform., vol. 1, no. 1, pp. 46-58, 2016. 